\title{
Multi-agent system to support decision-making process in design for recycling
}

\author{
Ewa Dostatni ${ }^{1}$ - Jacek Diakun ${ }^{1}$ - Damian Grajewski ${ }^{1}$. \\ Radosław Wichniarek ${ }^{1}$. Anna Karwasz ${ }^{1}$
}

Published online: 12 August 2016

(C) The Author(s) 2016. This article is published with open access at Springerlink.com

\begin{abstract}
In this paper, the application of multi-agent system to support decision-making process in design for recycling is presented. The design for recycling term is highlighted either as the design problem or from the point of view of regulations. The structure of agent system supporting the designer during the design process is showed. The basis of special kind of product model, that is the extension of standard 3D product model, called recycling-oriented product model, is described. The example results of analysis, based on real household appliance model, are presented.
\end{abstract}

Keywords Agent technology - Design for recycling · Product modeling $\cdot$ Product design

\section{Introduction}

The issues related to recycling and environmental protection are widely addressed in many scientific articles and are a major challenge for the society. Therefore, methods are developed that modify behavior and lead to increased effectiveness of processes related to environmental protection (Pessin et al. 2013; Woldt et al. 2003). However, the best results can be achieved when certain environmental requirements are taken into account already at product design stage.

Communicated by A. Herrero.

Jacek Diakun

jacek.diakun@put.poznan.pl

1 Faculty of Mechanical Engineering and Management, Poznań University of Technology, 3 Piotrowo, 61-138 Poznan, Poland
Designing a new product requires making many important decisions that must take into account a variety of different criteria. When a product is launched on the market, it must be tailored to the needs of the target consumers and bring tangible benefits. It is mainly the job of designers to achieve all the above; they should be able to predict the final effect of any project. The main problem related to design is the necessity to use uncertain information-to predict future conditions, which may not necessarily come true. The decision-making process by designers is mainly characterized by logic, directly shaped by the designers' knowledge and skills. However, there are also purely psychological factors, which include: nature and emotional status of the designer, as well as his or her work environment (Bạbiński 1964). To make the right decisions, the designer should above all be able to make use of all the available information and see the analogy in phenomena or problems that are different from or seemingly similar to each other. This allows him to use information from previous projects and may lead to significant reduction of project time, avoidance of errors made in other projects, etc. (Ellis 1962; Weiss and Dostatni 2011). Among the large number of decisions made during the life of the project, the most important ones include decisions concerning the options of design solutions, as they have a major impact on the quality of the design process. Currently, environmental aspects must also be considered at the design stage. The design of new products with a view to ensuring possibly lowest environmental impact throughout their lifetime is called ecodesign. Moreover, the possibilities of how the product may be managed at the end of its life are determined already at the design stage. This approach to design results mainly from the law of EU Member States than from actual market conditions; it is enforced by the legislation of the European Union (Directive 2003, 2005; ISO 2001). Additional decision-making criteria during the 
design process increase the volume of data processed by the designer, and thus making the right decisions is even more difficult. Apart from the typical criteria related to product functionality, its durability, quality and cost, the designer must take into account such issues as disassembly (time and cost), the environmental impact of materials used in the product, their compatibility and marking. To support and assist the designer, it is reasonable to develop a computer system, which could provide and process information in a way that very much facilitates the process of making the right decision. Such a system must be able to use dispersed sources of information and work efficiently in complex structures of design companies. The article presents the use of agent technology in recycling-oriented product assessment already at the design stage. The term "design for recycling" used in the paper means here: (1) including recycling data in product model and (2) taking into account recycling issues during the design process and thus is considered as part of ecodesign.

\section{The use of multi-agent systems in a distributed environment}

The terms "decentralized artificial intelligence" and "agent" emerged in the literature in the early 1980s, but dynamic development of IT solutions based on this paradigm ensued in the mid-1990s of the twentieth century. The interpretations of the agent's role are diverse (Brenner et al. 1998; Caglayan and Harrison 1998; Rao and Georgeff 1991; Wooldridge 1999) but undoubtedly have the following common features (Dostatni et al. 2013):

1. observation-agent dynamically perceives the environment's conditions and acts toward changing these conditions and determines activities in order to conduct its intentions,

2. autonomy-agents stay in a dynamic environment, perceive the environment and act autonomously, conduct actions according to their use; agents perform some sets of operation on behalf of a user of a different program, to some extent independently; they also use some knowledge that represents a user's goals or intentions,

3. mobility-ability of an agent to cooperate with other agents, dynamically adjusting intentions to changes in the environment and (in the case of some types of agents), ability to move in the network,

4. communication-agent communicates with the user, handles its tasks, reports actual status of tasks and their finalization; in order to fulfill these tasks, an agent uses special interfaces and communication languages,

5. intelligence-agent interprets the events and based on events makes decisions.
The features described above directed their applications in various areas. Nowadays, agent technology also has a broad application in production preparation and determines the new paradigm in computer-aided engineering (Van Dyke 1996).

To perform the task it was assigned, each of the programmed agents must have a certain level of intelligence. The intelligence of the agent allows for its independent operation without user intervention to complete the required task. Autonomous operation is one of the main features that distinguish intelligent agents from traditional software. To achieve its objectives, an agent integrates its activities with the surrounding environment. The agent sees the dynamic conditions of the environment, works toward changing them, and determines actions to achieve its own objectives. The agent, in its operation, may not be separated from the environment; it must communicate and cooperate with other objects, e.g. with other agents. The ability to communicate is considered to be a particularly important feature of agents, and by some authors it is even seen as the feature that distinguishes this type of software. Agents communicate with special communication languages (e.g. KQML—Knowledge Query and Manipulation Language or ACL-Agent Communication Language). The features mentioned above are important in ensuring proper coordination of tasks in the design process.

Specific features of the agents are used in communication technologies (Bigus and Bigus 1998; Weiss 1999; Amruta et al. 2014; Aziz et al. 2014a; Aziza et al. 2014b), data acquisition, aiding operations in distributed environments (Dent et al. 2001), simulation (Aziz et al. 2014a; Aziza et al. 2014b) and decision-supporting systems (Frayret et al. 2007; Nilsson and Darley 2006; Hilletofth and Lättilä 2012). Agents were also implemented for modeling and simulation of production systems (Jennings and Wooldridge 1998; Shen et al. 2000) and for integration of activities in specific manufacturing areas (Lu and Yih 2001; Yu et al. 2003; Park et al. 2003).

This broad scope of agent technology implementation motivated the authors to search for a new and innovative field of implementation toward supporting the activities in design for recycling. The agents follow the designers' activities, analyze the structure of the product being designed and conduct an analysis of the product, taking into account recycling issues. The agents suggest how to improve the product design in order to make it more environmentally friendly (Dostatni et al. 2013).

\section{Functionality of the agent system supporting design for recycling}

The agent technology is used in the system to support decision-making in the design of recycling-oriented products. The multi-agent system is to conduct a recycling- 
oriented assessment of a product designed in a CAD 3D environment, based on data from a product model (RmWrecycling product model) made in a CAD 3D system. The system makes it possible to control and monitor recycling parameters of products on an ongoing basis in subsequent versions of the design and suggests potential remodeling which may improve the parameters. It supports designers working in a distributed environment. Each designer who participates in the work on the project may work in a different node of the distributed network. He may use an IT tool (the agent system), which analyzes his work and based on the observations it conducts a recycling-oriented assessment of the product. Moreover, the system offers suggestions of construction modifications to improve the recyclability of the product (Dostatni et al. 2014).

The system cooperates with an existing CAD 3D extension, exporting the CAD 3D design to two XML files-a material database and a structural description of the product. The import is done automatically without the participation of the designer. Programmed agents read the information stored in the XML files and conduct the analysis. In the system, the software agents observe and acquire information, exchange it, and operate in a defined, common virtual environment. The key features of agents used in the system are:

1. autonomy - they make decisions and act only based on the interaction with the environment,

2. locality - no agent has (and does not need to have) complete information about the state of the system,

3. decentralization - there is no agent that directly controls the operation of the entire system.

Agents communicate with each other and observe information sent by other agents. In the multi-agent system, the agent environment is defined by a distributed message exchange service, implemented as a central server. It provides agents with three basic operations:

1. sending a message to the environment,

2. receiving messages (that match the given template),

3. reading a message (that matches the given template) but without deleting it from the environment.

Message exchange between agents in the system was developed based on table architecture and tuple spaces (Freeman et al. 1999; Costa et al. 2006). Every message sent in the system has a specific type and associated data. The basic template of a message is the type, although they may be more detailed. The tasks of the system are conducted by independent software agents, and each of them is in charge of a separate phase of the environmental product assessment. The agents coordinate their work using a common, central message server and the knowledge base.
The main task of the agents is to assist the designer in the selection of material, taking into account its ecological properties and compatibility with other materials, and in the selection of the type and number of joints. Based on a series of analyses, the agents advise which element of the designed product has the greatest adverse impact on the environment.

\section{Recycling-oriented product assessment}

\subsection{Recycling product model}

Modeling in CAD systems with the use of the agent system allows for a comprehensive assessment of the design solutions and improvement of their recyclability. During design, the following aspects are assessed: compatibility of materials used in product prototypes, types of joints and recyclability indicators (recycling target, among others). The IT tool used in the recycling-oriented analysis has a modular structure. The first module is used to operate the $\mathrm{RmW}$ - the recyclingoriented product model in the CAD 3D environment. The other one operates the agent system (product analysis, calculation of the evaluation measurements, collection and use of information on completed projects).

The recycling-oriented assessment of each product modeled in a CAD 3D system takes place according to the following stages:

1. development of a 3D geometrical model,

2. development of the RmW,

3. recycling-oriented product analysis.

The recycling-oriented product assessment, conducted by the system automatically already in the design phase, requires that a recycling-oriented product model $(\mathrm{RmW})$ be created. The model consists of the following elements (Dostatni et al. 2014):

1. extended product structure,

2. extended material attributes,

3. disassembly attributes (data on the disassembly process),

4. product categorization.

The extended product structure in $\mathrm{RmW}$ is based on the typical structure, created by the designer in the CAD 3D system and extended by additional data. Due to the significance of the joints used in the product and their impact on the recyclability and due to the lack of a clear representation of this construction feature in a standard 3D model, additional data were implemented, clearly and in detail describing the joints. Four basic assumptions concerning the representation of joints in the product were made: 
1. the representation of the broadest possible group of joints used in products should be considered in the model,

2. product components are divided into three groups: connecting elements (fasteners), combined elements and connecting-combined elements,

3. the joints in the 3D model will be represented in a method other than geometric constraints,

4. the model of joints will be coded in the 3D model using only typical mechanisms of 3D modeling.

It is a direct consequence of assumption 1 that the model may include the representation of all types of joints used in the electrical engineering industry. Currently, in 3D modeling systems the representation is selective, i.e. it includes only selected types of joints, most often by means of a specialized module (e.g. welded structures module in Autodesk Inventor 2012)

In the case of assumption 2, the division is as follows:

1. the first group includes primarily standardized parts, whose primary purpose is to connect parts and assemblies in the product. The group comprises screws, bolts, nuts, rivets, etc.

2. the second group includes those elements of the product, whose function is different than connecting parts,

3. the third group includes elements that combine the function of the connecting element with another function, not related to connecting (e.g. threaded parts of bodies).

The division above is functional, as it describes the functions of all components in the model, looking at their role in joints. Due to this feature of the discussed solution, such a model can be described as functional, focused on the structure of joints in the product (in short: a functional model of joints).

Within assumption 3 , it was decided that the representation of joints should be made by way of grouping selected elements of the model, where each group reflects a specific joint and additional attributes unambiguously describe (categorize) the joint. For this reason, the adopted method of defining joints-as logically related groups of elements-may be described (due to the analogy with geometric constraints) as functional constraints oriented to joint structure in the product (in short: functional joint constraints).

The practical implementation of the solution was preceded by developing a formal model, describing the joints used in the product. The model was based on the hypergraph — graph in which an edge can connect more than two vertices (Berge 1989). We call

$G=(K, C)$

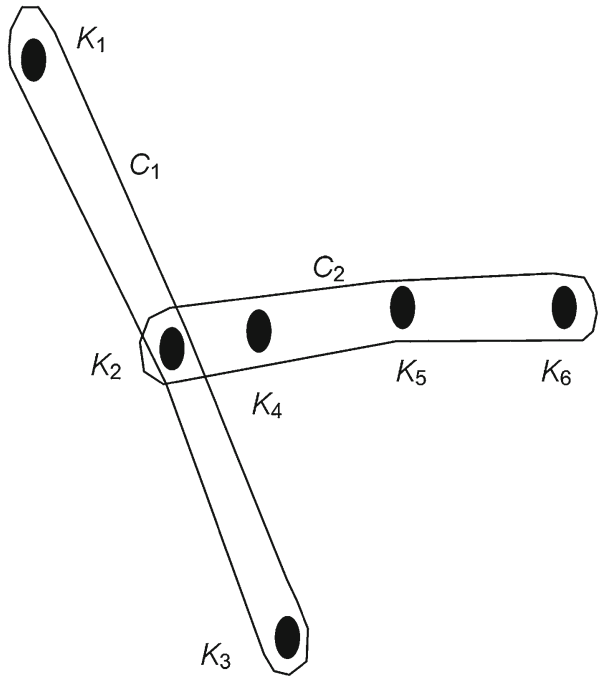

Fig. 1 Hypergraph $G=(K, C)$, where $K=\left\{K_{1}, K_{2}, K_{3}, K_{4}, K_{5}\right.$, $\left.K_{6}\right\}, C=\left\{C_{1}, C_{2}\right\}$ and its representative

a hypergraph where $K$ is set of vertices, and $C$ is the set of hyperedges (Fig. 1).

In the formal model of joints weighted hypergraph

$G=(K, C, w)$

was used, where $w$ is the set of weights.

In the adopted model, the vertices of the hypergraph represent the connected parts, or connecting-connected parts. The hyperedges (edges of the hypergraph) represent the joints (1 hyperedge $=1$ joint), and attributes of a given joint are represented by the hyperedge weights. The use of the hypergraph allows for a formally simple representation of a situation where more than two elements of a model are connected.

In the set of product parts- $P$ is the sum of sets $M, L$, and $M L$ :

$P=M \cup L \cup M L$

where $M=\left\{M_{1}, M_{2}, \ldots, M_{n}\right\}$ is the set of combined elements (parts and assemblies) and $L=\left\{L_{1}, L_{2}, \ldots, L_{k}\right\}$ is the set of connecting elements and $L=\left\{M L_{1}, M L_{2}, \ldots\right.$, $\left.M L_{m}\right\}$ is the set of connecting and combined elements.

The structure of functional constraints is described by a hypergraph:

$G=(K, C, w)$

where $K=M \cup M L$ and $C=\left\{C_{1}, C_{2}, \ldots, C_{i}\right\}$ is the set of hyperedges representing the joints (one hyperedge corresponds to one joint; it is at the same time a representation of a single functional constraint), and $w=\left\{w_{1}, w_{2}, \ldots, w_{i}\right\}$ 
is the set of hyperedge weights, representing the specific attributes of the joint.

The weight $w_{j}(j=1,2, \ldots, i)$ of the hyperedge is a triplet:

$w_{j}=\left(L_{j}, v, u\right)$

where $L_{j} \in L$ is the subset of the set of connecting elements and $\mathrm{v}$ is the attribute defining the type of joint $(v \in\{$ separable, inseparable $\})$ and $\mathrm{u}$ is the attribute determining the type of joint $(u \in\{$ welded, brazed, glued, riveted, thermocompressed, obtained through plastic working, fixed, flared, flanged, cleft, splined, keyed, threaded, forced-in, knuckle, studded, clicked-fit\}).

Example 1 Joint of two plates using two screws, two nuts and four washers (Fig. 2a):

$M=\left\{M_{1}, M_{2}, M_{3}, M_{4}, M_{5}, M_{6}\right\}$ - set of combined elements (plates and washers),

$L=\left\{L_{1}, L_{2}, L_{3}, L_{4}\right\}$-set of connecting elements (screws and nuts),

$C=\left\{C_{1}, C_{2}\right\}, w=\left\{w_{1}, w_{2}\right\}$-set of two weighted hyperedges (two joints between elements),

$C_{1}=\left\{M_{1}, M_{2}, M_{3}, M_{4}\right\}, w_{1}=\left(\left\{L_{1}, L_{2}\right\}\right.$, separable, threaded)—definition of separable threaded joint between plates $M_{1}$ and $M_{2}$, washers $M_{3}$ and $M_{4}$ using screw $L_{1}$ and nut $L_{2}$,

$C_{2}=\left\{M_{1}, M_{2}, M_{5}, M_{6}\right\}, w_{2}=\left(\left\{L_{3}, L_{4}\right\}\right.$, separable, threaded)-definition of separable threaded joint between plates $M_{1}$ and $M_{2}$, washers $M_{5}$ and $M_{6}$ using screw $L_{3}$ and nut $L_{4}$.

Example 2 Joint of two elements using clicked-fit joint (Fig. 2b):

$M L=\left\{M L_{1}, M L_{2}\right\}$ —set of connecting and combined elements,

$C=\left\{C_{1}\right\}, \quad w=\left\{w_{1}\right\}$ - set of one weighted hyperedge (one joint between elements),

$C_{1}=\left\{M L_{1}, M L_{2}\right\}, \quad w_{1}=\left(\left\{M L_{1}, M L_{2}\right\}\right.$, separable, clicked - fit)-definition of separable clicked-fit joint between elements $M L_{1}$ and $M L_{2}$.

The inclusion of the recycling-related issues into the tools that support the designer's work requires as well that the list of standard material attributes be expanded. This list has been expanded to include: harmfulness of material, material disposal cost, graphic designation of the material according to the standards and other legal acts on the requirements for materials used in the product.

Another element to be taken into account in the tools supporting the work of the designer is the combination of

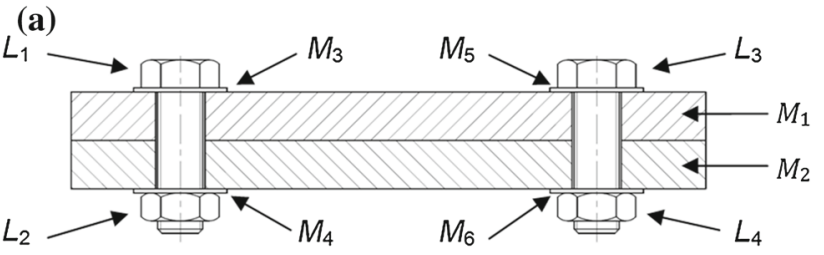

(b)

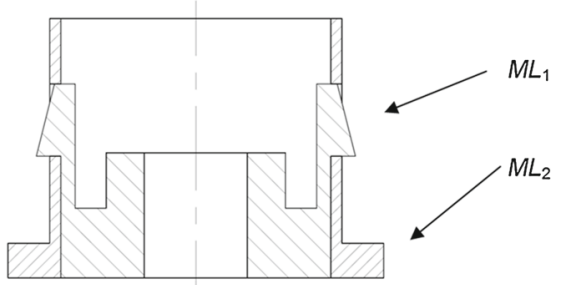

Fig. 2 Examples of joints: a separable with combined (plates and washers) and connecting (screws and nuts), b separable with connecting and combined elements

materials in the so-called groups (in which different materials are grouped together) and determining the so-called compatibility of each group of materials. Compatibility is understood here as the recyclability of a piece of the product (an entire assembly or several combined elements) as one element. Determining the compatibility of groups of materials, we indirectly determine the compatibility of two materials.

In the proposed solution, we assumed that recycling of the product will involve a nondestructive disassembly. Thus, the basic (elementary) disassembly operation will be to dismantle the joints in the product. Therefore, on a given level of product structure the components are considered disassembled when all joints have been dismantled. The data characterizing the disassembly include: dismantling a joint during disassembly, the tools used in the dismantling operation and the time needed to dismantle the joint. Dismantling a joint is a logical attribute yes/no (subject to dismantling/not subject to dismantling). In the existing regulatory framework, some products (such are domestic appliances) were divided into groups and certain minimum requirements were set for their recycling targets. Assigning the product to a given group is the final element of the $\mathrm{RmW}$, and it allows for a direct comparison of the product assessment values resulting from the legal regulations with the current values at a given stage of design or analysis. As a result, already at this stage we may verify whether the designed product meets the legal requirements laid down for this group, which determines whether the product may be introduced on the market.

\subsection{Measures of the recycling-oriented product assessment}

The authors developed a new method to conduct a recyclingoriented product assessment, based on indices, tooltips and suggestions (to modify the construction parameters of the 
designed product thus improving the recyclability parameters of the designed product). The method takes into account the guidelines contained in the directives and standards that must be taken into account in the ecological product design (ISO 2001).

Recycling-oriented product assessment is based on a unique recycling rate CWR (total recycling rate). It is the sum of three subindices (Dostatni et al. 2013):

$$
\mathrm{CWR}=\mathrm{WRM}+\mathrm{WRP}+\mathrm{WPR}
$$

where WRM is the material diversity, WRP is the joint diversity and WPR is the recycling target.

The subindices are minimants: the lower their value, the easier the recycling. They are determined indirectly by calculating the quantitative ratios.

When formulating the rate of material diversity (WRM), the authors adopted the assumption that the smaller the number of different materials, the easier the recycling. If the product is made of elements made of the same materials (or compatible materials), recycling is easier and faster than when each element is made of different material. In the latter case, all the elements should be separated for recycling. This prolongs the disassembly and increases its cost. The percentage of material diversity is calculated using the following formula:

$W_{\mathrm{RM}}=1-\frac{M_{1}}{M_{W}}$ where $M_{1}$ the number of occurrences of material most frequently used in the product and $M_{W}$ the number of occurrences of other materials used in the product.

To learn the percentage of material diversity $W_{\mathrm{RM}}$ one can find the value of material diversity-WRM in Table 1. For example, if material A was used 3 times in the product, and materials $\mathrm{B}$ and $\mathrm{C}$ were each used once, then $W_{\mathrm{RM}}[1-3 /(3+$ $1+1)]=40 \%$, and WRM is 2 (Table 2 ).

The percentage of the diversity of connections (WRP) is calculated as follows:

$W_{\mathrm{RP}}=1-\frac{P_{1}}{P_{W}}$

where $P_{1}$ the number of occurrences of joint most frequently used in the product and $P_{W}$ is the number of other joints in the product.

To learn the percentage of joint diversity WRP, one can find the value of joint diversity-WRP in Table 3. For example, if joint $\mathrm{A}$ and $\mathrm{B}$ were each used 2 times in the product, and joint $C$ was used once, then WRP $[1-2 /(2+2+1)]=60 \%$, and WRP is 3 .

To formulate the rate of joint diversity - WRP, the authors adopted the assumption that the fewer types of joints are used in product, the easier and faster the recycling, and thus the lower its cost. Smaller diversity of joints in the product facilitates disassembly, as there is no need for frequent change of tools. If the disassembly is automatic, it is not necessary to adjust the disassembly line to a large number of different types of joints. It is best when all joints are separable. The disassembly of the product is simple. When there are many

Table 1 Conversion of WRM to WRM

\begin{tabular}{lllllllllll}
\hline$W_{\mathrm{RM}}(\%)$ & $\leq 10$ & $\leq 20$ & $\leq 30$ & $\leq 40$ & $\leq 50$ & $\leq 60$ & $\leq 70$ & $\leq 80$ & $\leq 90$ & $\leq 100$ \\
\hline$W R M$ & 0.5 & 1.0 & 1.5 & 2.0 & 2.5 & 3.0 & 3.5 & 4.0 & 4.5 & 5.0 \\
\hline
\end{tabular}

Table 2 Comparison of WRM (rate of material diversity) for products of varied complexity

\begin{tabular}{|c|c|c|c|c|c|c|}
\hline \multicolumn{5}{|c|}{ Number of parts } & \multirow[t]{2}{*}{$W_{\mathrm{RM}}$ rate calculated from formula (2) } & \multirow[t]{2}{*}{$\overline{\text { WRM rate from Table } 1}$} \\
\hline Type A & Type B & Type C & Type D & Total & & \\
\hline 3 & 1 & - & - & 4 & $1-(3 / 4)=25 \%$ & 1.5 \\
\hline 3 & 2 & - & - & 5 & $1-(3 / 5)=40 \%$ & 2.0 \\
\hline 3 & 1 & 1 & - & 5 & $1-(3 / 5)=40 \%$ & 2.0 \\
\hline 3 & 3 & 2 & - & 8 & $1-(3 / 8)=63 \%$ & 3.5 \\
\hline 2 & 2 & 1 & - & 5 & $1-(2 / 5)=60 \%$ & 3.0 \\
\hline 2 & 1 & 1 & 1 & 5 & $1-(2 / 5)=60 \%$ & 3.0 \\
\hline 2 & 2 & 2 & 2 & 8 & $1-(2 / 8)=75 \%$ & 4.0 \\
\hline
\end{tabular}

Table 3 Conversion of WRP to WRP

\begin{tabular}{lllllllllll}
\hline$W_{\text {RP }}(\%)$ & $\leq 10$ & $\leq 20$ & $\leq 30$ & $\leq 40$ & $\leq 50$ & $\leq 60$ & $\leq 70$ & $\leq 80$ & $\leq 90$ & $\leq 100$ \\
\hline WRP & 0.5 & 1.0 & 1.5 & 2.0 & 2.5 & 3.0 & 3.5 & 4.0 & 4.5 & 5.0 \\
\hline
\end{tabular}


inseparable joints, most often the disassembly is abandoned due to high costs. If the materials connected inseparably are not compatible, the product does not qualify for recycling.

The percentage of recycling target WPR is calculated as follows:

$W_{\mathrm{PR}}=\frac{M_{\mathrm{R}}}{M_{\mathrm{W}}}$

where $M_{\mathrm{R}}$-total weight of all recycled elements and $M_{\mathrm{W}}$ total product weight.

To learn the percentage of recycling target WPR, one can find the value of recycling target-WPR in Table 4. For example, if the product weighs $5 \mathrm{~kg}, 4 \mathrm{~kg}$ of which are suitable for recycling, the recycling rate is $[4 / 5]=80 \%$.

The value of recycling rate weight coefficient WPR depends on the group of household appliances the designed product belongs to. Recycling rates of all product groups are defined in the WEEE directive.

Below are the groups of products, their minimum recycling rates and the respective WPR value.

The minimum recycling rates (Table 4):

1. for large household appliances (group 1) and vending machines (group 10)-75\%,

2. small-size household appliances (group 2)-50\%,

3. IT and telecommunications equipment (group 3 ) and consumer equipment (group 4)—65\%,

4. lighting equipment (group 5), electrical and electronic devices with the exception of large stationary industrial tools (group 6), toys, leisure and sports equipment (group 7 ), instruments for monitoring and control (group 9)$50 \%$.

It was also assumed that if the designed product does not reach the minimum rate required under the regulation, then WPR is set to 15 (which shows the designer that the product does not comply with the regulation), and if the product meets the minimum or exceeds it, then the value of the rate will be taken from the relevant table.
The recycling cost $K_{\mathrm{WR}}$ is the difference between the profit from selling recyclable and reusable materials, and the total cost incurred for disassembly, disposal of hazardous waste and transport to waste disposal landfill:

$K_{\mathrm{WR}}=\sum_{i=1}^{n} K_{\mathrm{MD}}-\left(\sum_{i=1}^{n} K_{\mathrm{UMN}}+\sum_{i=1}^{n} K_{\mathrm{Odpad}}+\sum_{i=1}^{n} K_{\mathrm{Dem}}\right)$

where $K_{\mathrm{MD}}$ is cost of good materials (recyclable and reusable), $K_{\mathrm{UMN}}$ is cost of hazardous waste treatment, $K_{\text {Odpad }}$ is cost of waste and $K_{\text {Dem }}$ is disassembly cost.

The method described above was implemented in an agent system. Since the calculated values must be consistent with standards, and the recycling rate changes (in changes year after year), the editor of product groups and minimum recycling rates was added to the system. The rates constitute measures according to which the product can be assessed in terms of its suitability to recycling. The rates can be defined both for the entire product and for a selected product part. In this way, it is possible to determine the impact of the selected part on the rate values of the entire product.

\subsection{Suggestions and tips}

For the purposes of the recycling-oriented product assessment, a tips and suggestions method was developed to improve the product's recyclability parameters. The suggestions include:

1. changing the material,

2. changing the joint from inseparable to separable (thus allowing for the disassembly).

The information that the designer approves type (1) suggestions is saved in the suggestion base (e.g. material A was changed to material B). As a result, when material A may be changed to some compatible materials, the system will arrange the suggestions according to the frequency of their actual application. Similarly with type (2) suggestions: the
Table 4 Weight ratio of the product recycling rate

\begin{tabular}{|c|c|c|c|c|c|c|c|}
\hline Group & 1,10 & & & & & & \\
\hline Recycling rate & $<0-75)$ & $<75-80)$ & $<80-85)$ & $<85-90)$ & $<90-95)$ & $<95-100)$ & 100 \\
\hline WPR & 15 & 4 & 3 & 2 & 1 & 0.5 & 0 \\
\hline Group & $2,5,6,7$ & & & & & & \\
\hline Recycling rate & $<0-50)$ & $<50-60)$ & $<60-70)$ & $<70-80)$ & $<80-90)$ & $<90-100)$ & 100 \\
\hline WPR & 15 & 4 & 3 & 2 & 1 & 0.5 & 0 \\
\hline Group & 3,4 & & & & & & \\
\hline Recycling rate & $<0-65)$ & $<65-70)$ & $<70-75)$ & $<75-80)$ & $<80-90)$ & $<90-100)$ & 100 \\
\hline WPR & 15 & 4 & 3 & 2 & 1 & 0.5 & 0 \\
\hline
\end{tabular}


system saves information, e.g. that joint A was changed to joint B.

Based on the value of the total recycling rate (CWR) and on the classification of the product elements, the system suggests the user to introduce changes, which will improve the value of the rate. The system suggests changing the elements, which cannot be disassembled and which are connected to incompatible materials. That may be done in two ways:

1. by changing the joint to a separable and marked as subject to disassembly,

2. by changing the material from which the element is made to a material compatible with other materials in the inseparable joint.

The designer may choose from many types of joints and compatible materials. Suggestions offered by the system may help in making the decision. The suggestion is based on the tip, which results from the static analysis of the design, and on the data collected by the system - the history of approved suggestions. The data are used to further detail the tips found. For example, a tip may be to change the material of which $\mathrm{E}$ element is made: from $\mathrm{M}$ material to one of the compatible materials: $X, Y, Z$. The historical data show that designers changed material $M$ to material $X 10$ times, to material $Y-5$ times, and the change to material $Z$ has not been recorded yet. In this case, the priority suggestion will to be to change material $M$ in element $E$ to material $X$, the secondary suggestion will be to change the material to $Y$, and the change to material $Z$ will remain a tip. The recycling-oriented product assessment method was implemented into a system based on agent technology supporting product recyclability evaluation.

\section{The structure of the multi-agent system}

Figure 3 shows the general architecture of the agent system. The agent system is responsible for maintaining the agent environment and for the access to the knowledge base agent, which allows the system to retain the information on the history of suggestion evaluation and on the history of project versions. The knowledge is used to provide suggestions to improve the recycling rate of the designed product. One agent server handles all the agents of the system. The agent server does not require any configuration, and it only provides the possibility to observe the recorded knowledge base.

During the recycling-oriented analysis of the product, the agent server temporarily stores messages from the agent environment. The messages are hidden and are not available to the user. It also saves the successive versions of the analyzed designs together with previously suggested modifications and complete results of the recycling-oriented analysis. The data are necessary to demonstrate differences between the

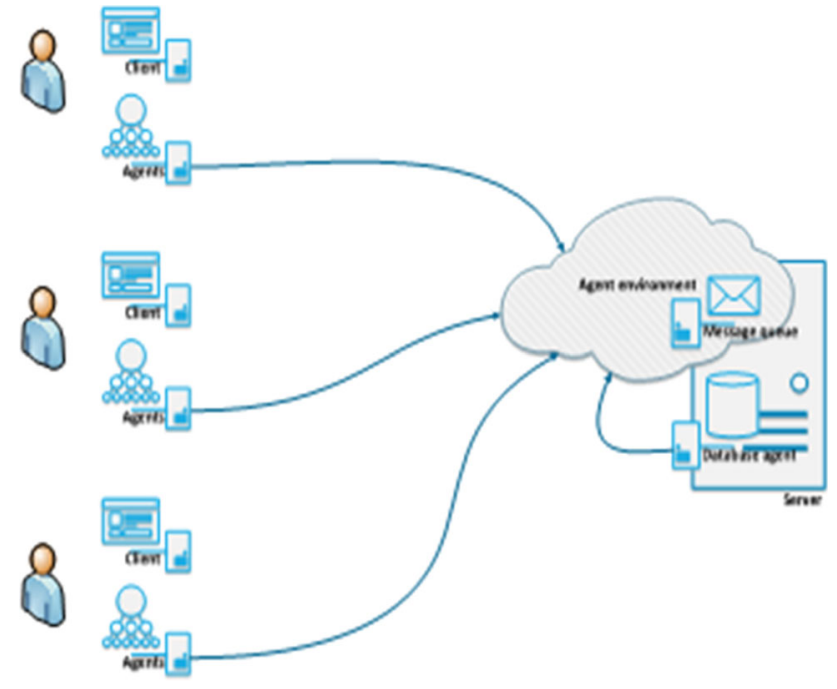

Fig. 3 General architecture of the agent system supporting ecodesign (Dostatni et al. 2014)

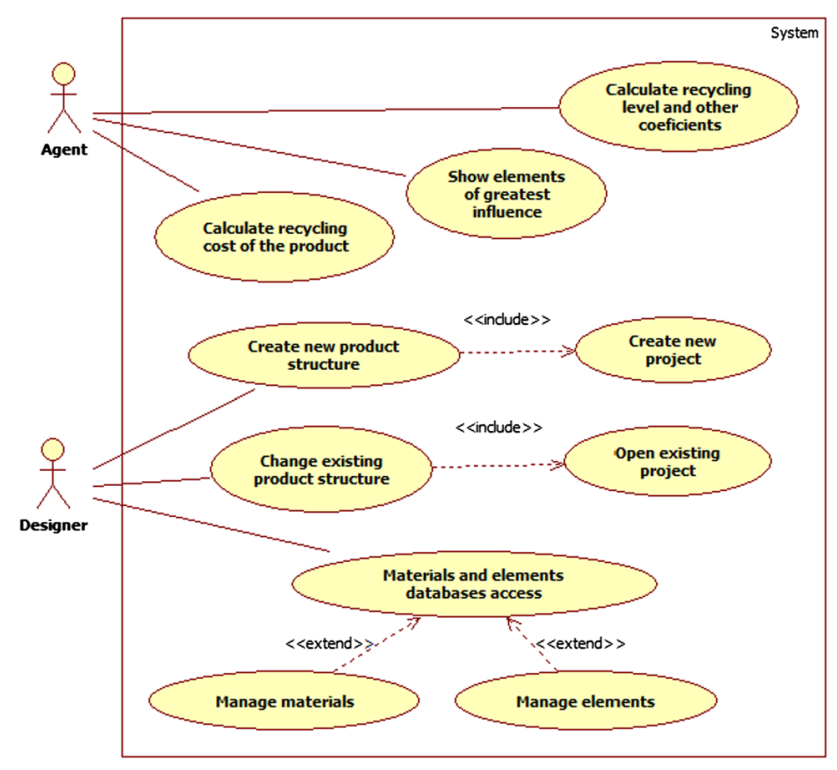

Fig. 4 Use case diagram (Dostatni et al. 2014)

successive versions of the design, and they give the user the possibility to monitor the changes in recycling rates. They constitute the knowledge resources necessary to offer suggestions to the designer.

The functionality, principle of operation and the architecture of the agent system are represented by selected UML diagrams: use case diagram (Fig. 4) and sequence diagram (Fig. 5). The use case diagram shows a review of possible actions made by individual users in the agent systems. The sequence diagram shows the dynamic aspects in the scenario of actions, which include complex interactions between the system objects (end user, agents, and knowledge database). 


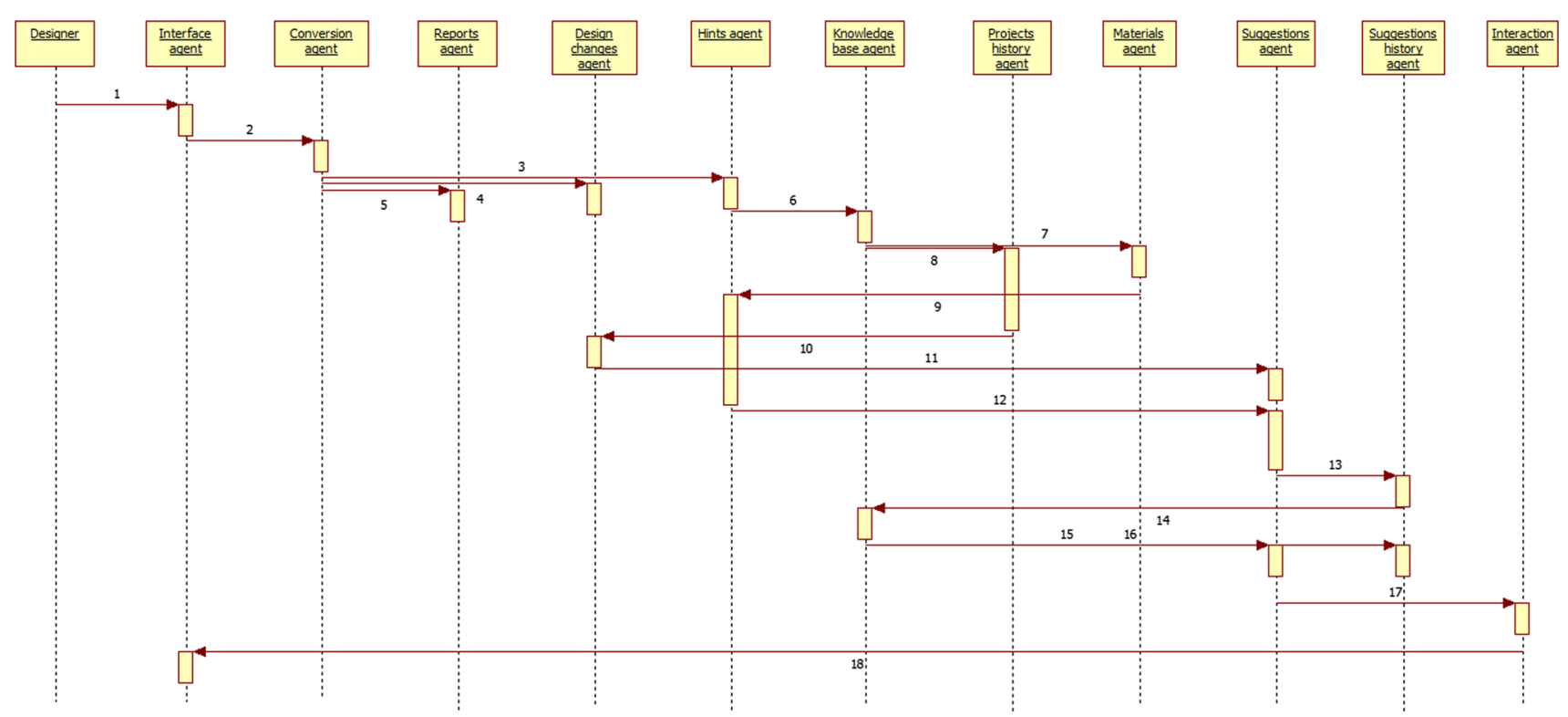

Fig. 5 Sequence diagram (Dostatni et al. 2014)

Due to its complexity, the recycling analysis algorithm developed by the authors constitutes the element of the system which has the largest demand for computing power, but it is not the only factor determining the waiting time for user to obtain system results. The working time of single recycling analysis is mainly determined by the number of joints specified by the user in the given product. The user may request that the agent system perform another analysis only after having received the data from the previous query. However, due to the fact that the agent system can simultaneously handle queries from multiple users, more queries for recycling analysis may be submitted at the same time. The authors conducted a performance test of the system to determine the influence of the number of product joints and simultaneous queries on the total working time of the system. As there are many factors determining the absolute working time of the system (client computers used, server, IT network, etc.) in the results shown in Fig. 6 the authors used relative working time of the system.

The reference point is the shortest measured times1 analysis for a model with 5 declared joints. The graph clearly shows that as the number of agent system users increases, the dependency between system working time and the level of recycling model compilation grows. The larger the number of system users, the faster the dependency changes from linear to logarithmic. This is crucial from the point of view of an individual user, as it determines the time in which he receives a response from the agent system. On the other hand, taking into account the work conditions (number of designers, product complexity) in typical design departments in small and medium enterprises in the household appliance industry, the system should

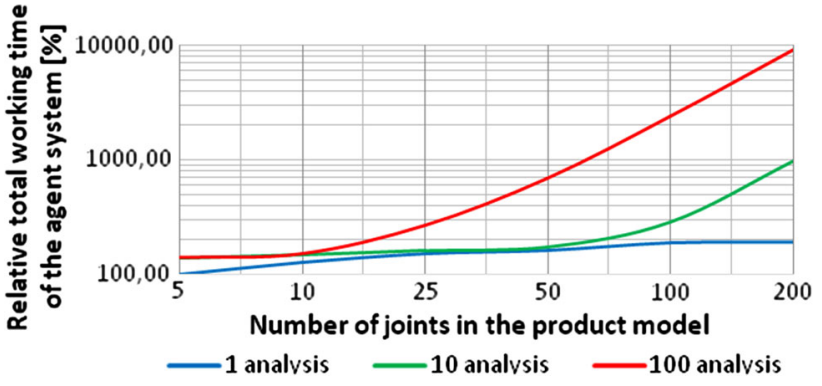

Fig. 6 Dependency between the number of joints used in the product model and the number of queries, and the total working time of the agent system

respond the user within an acceptable time-up to a few seconds.

From the point of view of the agent system as a whole, the best performance-defined as the time necessary to calculate a single constraint in the model — was achieved for a package of 100 analyses with a complexity of 25 constraints for each analysis (Fig. 7).

\section{Tasks of the agents}

There are two types of agents in the system. The first type is generally referred to as agents, and the other one as microagents. Agents are: the interface agent, conversion agent, the structural agents (which consist of microagents), design modifications agent, tips agent, material agent, report agent and the integration agent. The microagents are: order agent, update agent, joint control agent, weight update agent, agent 


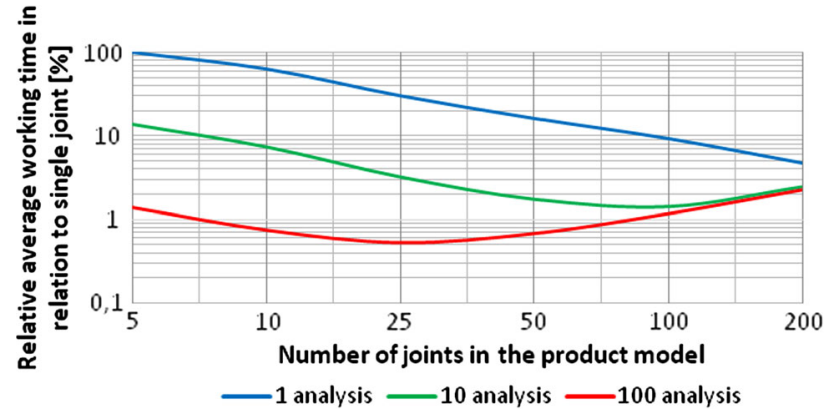

Fig. 7 Dependency between the number of joints used in the product model and the number of queries, and the total working time of the agent system in relation to a single constraint

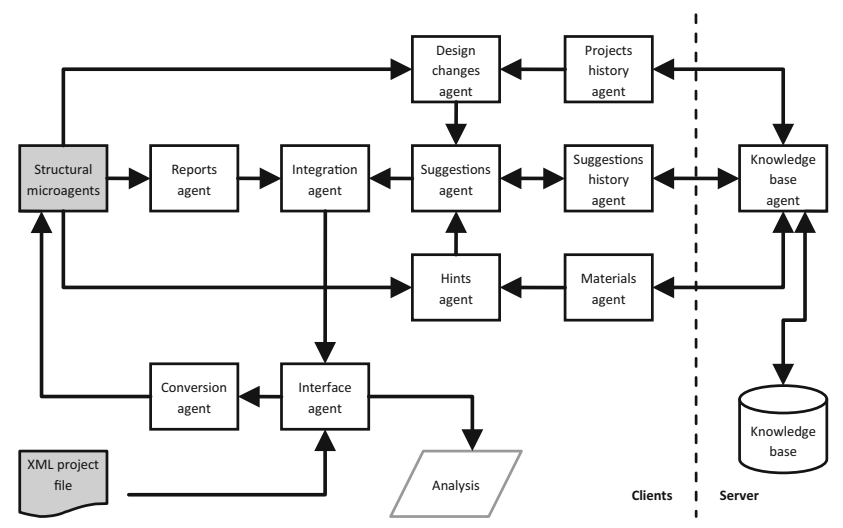

Fig. 8 Diagram of the agent system (Dostatni et al. 2014)

counting the joints, agent counting the materials and the measurement agent. Figure 8 shows a diagram of the agent system.

Agents operate according to the following sequence:

Stage 1: Interface agent starts the analysis-upon the request of the user (first launch of the agent system-the start of work) or after detecting a change in the design.

Stage 2: Conversion agent reads data from the 3D CAD system.

Stage 3: Structural agents perform the recycling analysis of the product.

Stage 4: Structural agents provide design data to the report agent and change analysis agents.

Stage 5: Report agent prepares a complete compilation of data for the report.

Stage 6: Design change agent compares the current design version with the previous version and analyzes the changes.

Stage 7: Tip agent analyzes possible advantageous changes of materials.

Stage 8: Tips and suggestions are forwarded to the suggestion agent.

Stage 9: Suggestion agent evaluates the received suggestions. The suggestions which were already used as suggestions are changed to suggestions with appropriate weight.
The suggestion history is common to all the designs analyzed by the agent system.

Stage 10: Integration agent prepares all the data (and possibly errors) for the interface agent.

Stage 11: Interface agent completes the analysis in the agent system and presents them to the user.

\section{Recycling-oriented design with the use of the agent system}

The agent system supporting green, recycling-oriented design features the following functions (Dostatni et al. 2014):

1. analysis of product structure, including the logical correctness of the defined joints between elements-the design is the process in which data are supplemented in stages, in certain situations; when the stored data do not allow for a clear description of the product, further analysis could yield meaningless results; the aim of this function is to detect these moments and blocks further analysis,

2. automatic calculation and updating the weight of components,

3. detection of changes made to the product design by the user-product design analysis is started when modifications are detected; the user will have access to current information,

4. calculating statistics and recyclability indicators of the entire product and its individual elements,

5. detecting changes in the recycling rate and recyclability indicator - thanks to the feature the user can see which changes in the product structure caused the increase, reduction or exceeding of acceptable levels and rate of recycling,

6. detecting and identifying elements, inseparable and incompatible elements,

7. detecting and identifying elements that have the greatest negative impact on the recycling rate,

8. creating a numerical summary of the used materials and types of joints,

9. detecting the use of hazardous materials (based on extended material attributes in $\mathrm{RmW}$ ) and warning the user,

10. suggestions and tips on changing materials or joints to improve recyclability parameters of the designed product,

11. creating reports.

As already mentioned, one of the basic tasks of the system is to offer tips and suggestions to improve the recyclability parameters of the product. 
All tips and suggestions are displayed according to the rules stored in the knowledge base of the agent system. The rules under which the agent system suggests material or joint changes to the designer (to improve product recycling rates) are stored in the design change agent and in the tips and suggestions agent, and the resources necessary to make appropriate decisions (knowledge resources) are stored in the design history agent, suggestion history agent and in the knowledge database.

After the first recycling-oriented product assessment (which had to be initiated by the user), the system will automatically monitor the work of the designer in CAD 3D system. Having detected any changes in the designed product, the interface agent requests that another recyclingoriented product analysis be performed.

\section{Case study}

The assessment procedure of a product designed in CAD 3D environment, based on the RmW model, will be presented on the example of a small household appliance: a hand mixer (Fig. 9).

In the first stage geometric CAD 3D models of 74 product elements were prepared, and the models of 17 elements (bolts, nuts, screws) were loaded from the library of standard parts in the CAD 3D. Next, an assembly model of the product was created. The constraints necessary to determine geometric relations between the parts were defined. The main assembly of the hand mixer consisted of six major components. After a positive verification proving that geometric constraints were designated correctly, the CAD 3D product assembly model became the basis for initiating the construction of the recycling product model $(\mathrm{RmW})$.

The construction of the RmW model required that all the basic attributes of the model be defined (connected parts, connecting parts, materials, types of joints to be used in the product, etc.).

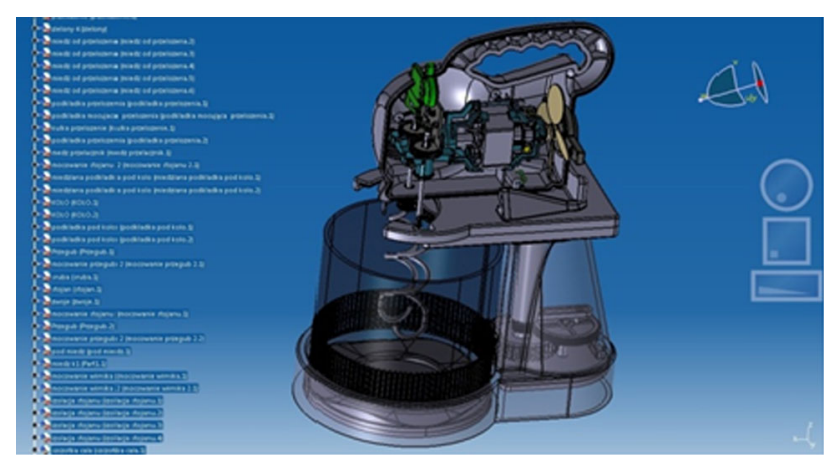

Fig. 9 Hand mixer-3D assembly model with a active view of product parts (Dostatni et al. 2014)
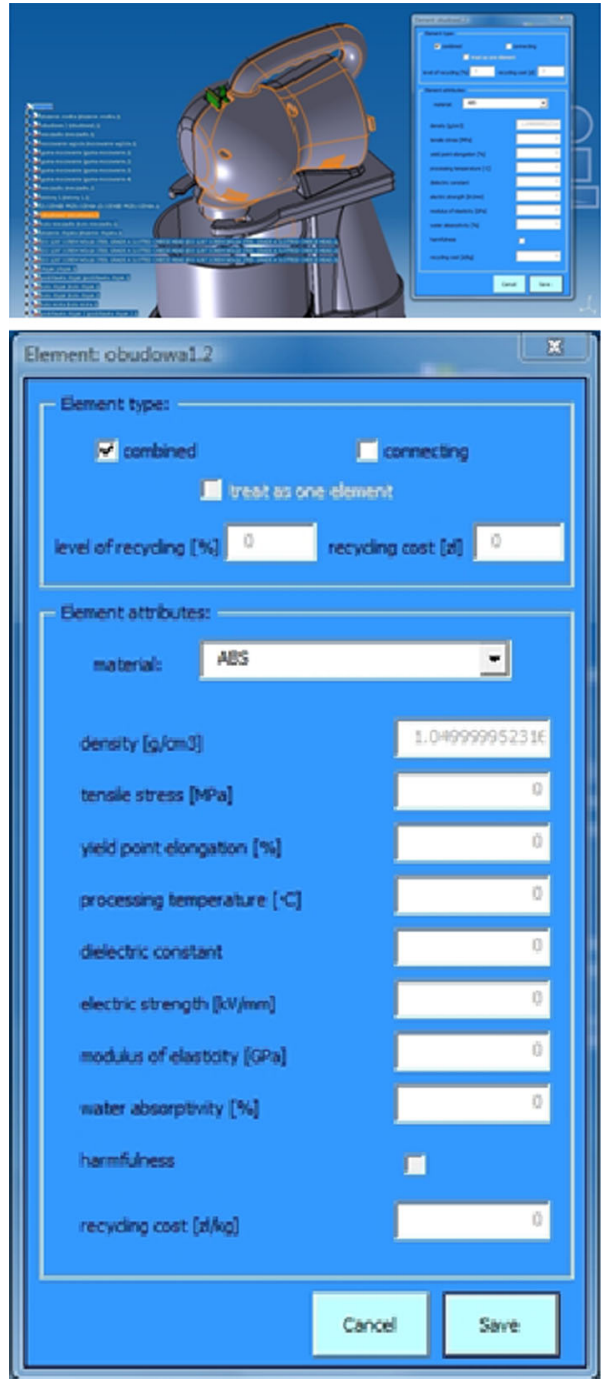

Fig. 10 Edition of combined element properties at any stage of the design process (Dostatni et al. 2014)

$\mathrm{RmW}$ attributes in the CAD 3D system were defined through a graphical user interface. The material database, defined in advance in an XML file, is available in the material base signature window. The database includes the basic groups of construction materials and plastics. Each material defined in the database is described by the basic material attributes and properties. The database includes also basic material groups and the compatibility matrix. It is possible as well to save in the database information needed for the disassembly process and the information on the existing material mixtures.

In the next stage the group to which the part belongs is determined (combined or connecting element), and from what material it is made (Figs. 10, 11).

The job of the user is to determine the material of each product part. When CAD 3D model assemblies are very complex and it is not necessary to disassemble the given 


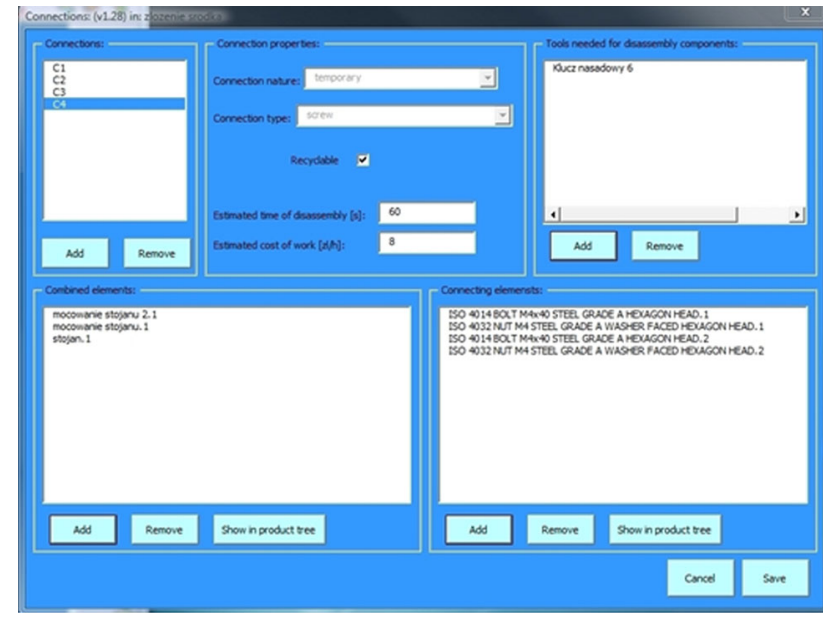

Fig. 11 Edition of joints in the stator component (Dostatni et al. 2014)

product component (as it is made of compatible materials, or includes inseparable joints and the materials are not compatible or are hazardous), the user can instruct the system not to subject the internal structure of the component to the recycling analysis (option "treat as one element"). In the latter case, two additional parameters may be introduced to describe such a component of the assembly: level of recycling, expressed in percent, and the cost of recycling, expressed in PLN.

Having determined the properties of all elements, it is necessary to complete the information about joints to be used in the designed product (Fig. 11).

The process of defining joints should begin with adding a new joint from the list of predefined joints. Next, the type of joint should be defined. If the joint is to be disassembled during recycling, it is necessary to select the option Recyclable. Finally, the user has to define the estimated time of disassembly of the joint (in seconds) and the estimated cost of disassembly (in PLN per hour). These data should be given by recycling specialist involved in product design or estimated based on the information obtained from recycling industry. Both values determine the estimated cost of work of a disassembly work station.

Each joint must consist of at least two combined elements, so the algorithm that verifies the correctness of data prevents the user from saving the information before this basic condition is met. The list of elements which make up any joint can be viewed and edited. An element to be included into a component must meet the following criteria:

1. its immediate parent element in the product structure is the element for which a joint is being created,

2. it is a combined element,

3. it does not belong to the combined elements of the created joint.
In turn, an element added to a list of connecting elements must be consistent with the following:

1. its immediate parent element in the product structure is the element for which a joint is being created,

2. it is one of the connecting elements,

3 . it does not belong to the connecting elements of the created joint.

The minimum number of connecting elements required for a joint to be considered correct depends on the type of the joint. The defined joint should include information about the tool to be used for disassembly for recycling. Information about all joints in the model is introduced in the same way.

Using the developed software, which takes the form of macros run in CAD 3D system, the attributes of the recycling product model $(\mathrm{RmW})$ were defined. All the recyclingrelated data gathered during the design process are stored in native $\mathrm{CAD} 3 \mathrm{D}$ files.

Using data exchange interface between 3D CAD system and the agent system, developed for this project, $\mathrm{RmW}$ data are transferred to the agent system. A universal data exchange format XML is used here. The XML file is generated by algorithms developed by the authors and entered into the 3D CAD system. At this point, it is possible to initialize the recycling-oriented analysis with the support of the agent system.

The system performs the recycling-oriented analysis of the household appliance. When the analysis is completed, the results of calculations are shown in the window of the agent system. Information on the positive completion of the analysis will also appear in the quick launch window (Fig. 12).

As a result of the recycling-oriented analysis of the discussed appliance, the obtained CWR ratio $=6.0$ and the recycling rate were $90.24 \%$. Material diversity (WRM) in the appliance was estimated at $58 \%$, which according to the conversion table equals 3.0. In turn, the joint diversity rate WRP was $39 \%$ (equal to 2.0). The recycling rate WPR, calculated as the relation between the total weight of recyclable elements to the total product weight, was $90.24 \%$. It is worth noting that the value of recycling rate WPR depends on the group of household appliances the designed product belongs to. For the analyzed product, which belongs to the group of small-size household appliances, the weight coefficient is 1.0 .

The results were satisfactory from the point of view of the designer, and they were consistent with the EU requirements and directives, among others regarding the recovery of materials. If the results of analysis were not satisfactory, the designer would have to take action to optimize solutions applied in the model (e.g. by modifying joints and materials: compatible, incompatible, hazardous). 


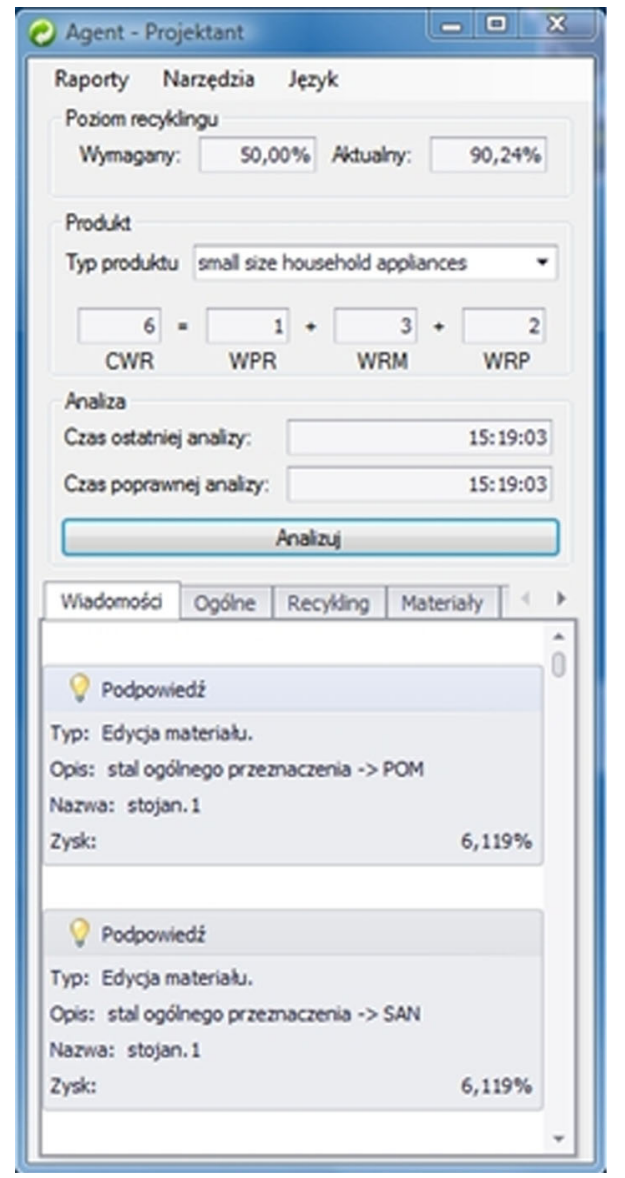

Fig. 12 Agent system window after the completion of the analysis (calculation of the CWR coefficient, Dostatni et al. 2014)

Thanks to the specially developed algorithm, it is also possible to assess the impact of each element or component on the overall recycling rate (CWR) for the product. The information is stored in columns Gain and Loss in the Recycling tab (Fig. 13).

The system performs a similar analysis of materials from which different parts of the product are to be made. The designer receives information about the material diversity of each component in the product. Columns Gain and Loss in the Materials tab store information on the impact of each component and its material diversity on the recycling-oriented assessment of the entire product. Material diversity in the designed prototype of a new household appliance should be as small as possible; therefore, reducing the diversity is seen by the agent system as gain-unlike in the case of recycling.

Similarly, the agent system presents information about joint diversity in the analyzed product. Columns Gain and Loss in the Joint tab store information on the impact of each component (its joint diversity) on the recycling-oriented assessment of the product. The diversity of joint should be reduced to a minimum; hence, actions resulting in lower joint diversity are seen as gain.

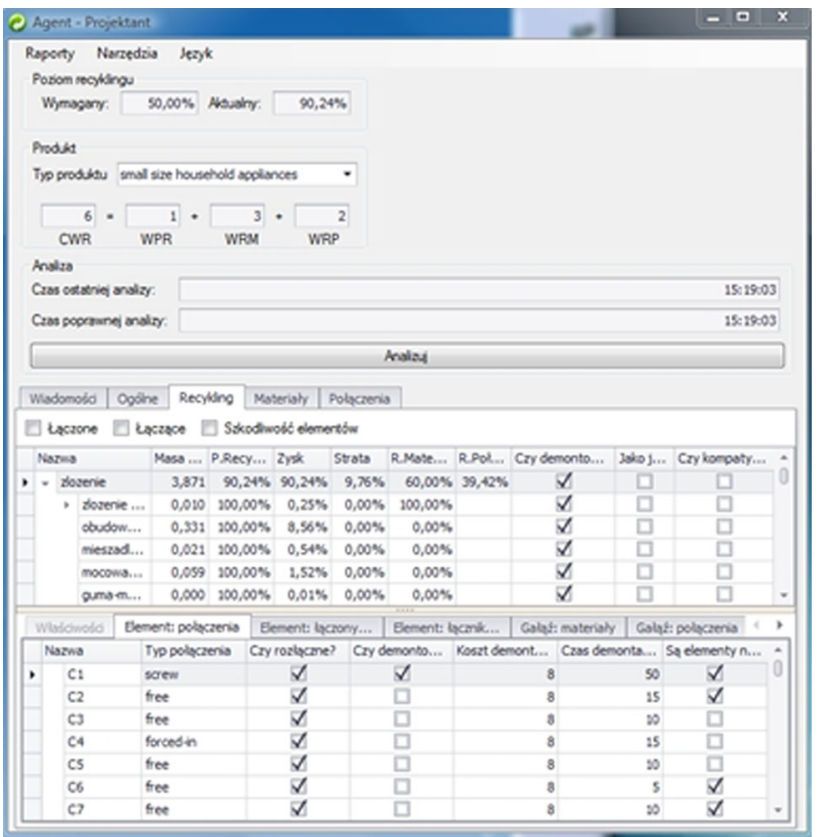

Fig. 13 The agent system window after the analysis (information about the rate of recycling of each element, Dostatni et al. 2014)

When the agent system finds errors during the recyclingoriented product analysis (for example, inconsistency in the product structure), it will automatically display a special message. If the error is associated with an analyzed component or product, complete information is displayed in the window Messages.

If the analysis is performed without any interruptions, the Messages window displays a list of hints and suggestions provided by the system (Fig. 14).

To verify the hints and suggestion module, the materials used in the selected parts of the stator assembly (stator and rotor fastening) were changed to worse ones in terms of recyclability (incompatible with other materials used in the component, thus requiring its disassembly). The system automatically detected the changes and pointed out a better solution-in this case, changing the materials for the parts to compatible materials or changing the selected joints-to improve the calculated rates.

Two reports are created after the recycling-oriented product analysis: a general and a detailed one. The general report includes the following: the required recycling rate, the actual recycling rate, product weight, disassembly potential, recycling cost, number of materials in the product, number of tools to be used for disassembly. In turn, the detailed report includes information on the required/actual recycling rate, the values of calculated recycling rates, the list of hazardous materials, the list of materials used in the product and a list of all joints in the design.

The analysis performed by the system made it possible to conduct a recycling-oriented product assessment. The reports 


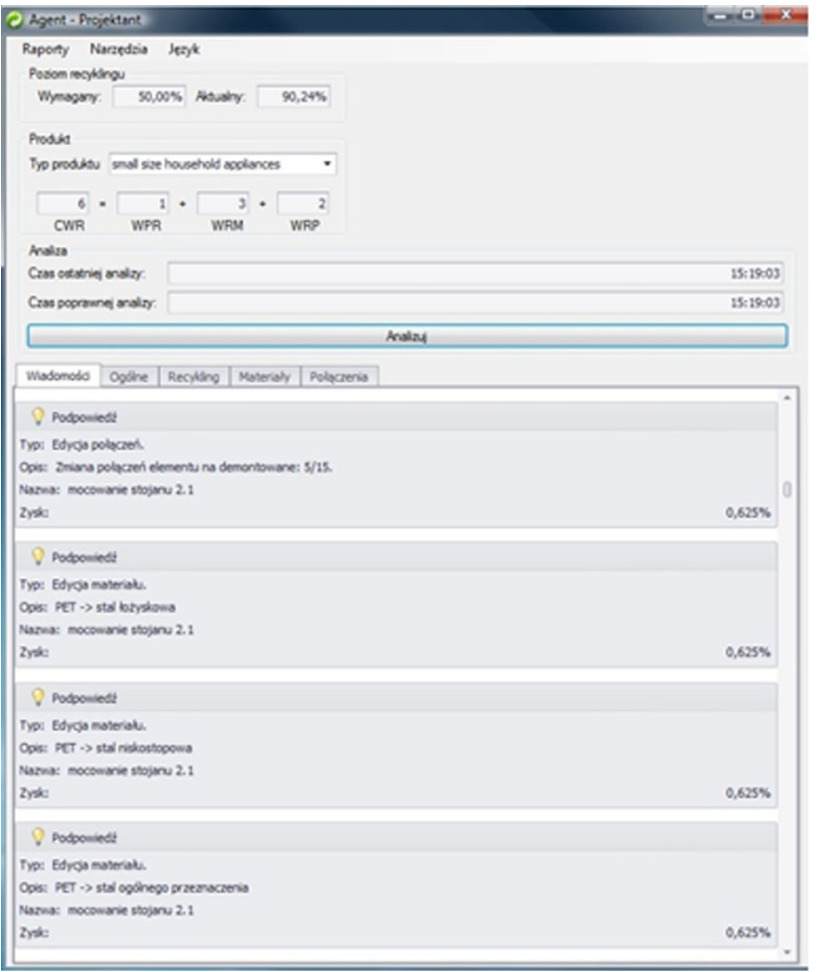

Fig. 14 The agent system window after the analysis (hints and suggestions, Dostatni et al. 2014)

may be the basis for determining whether the designed product meets environmental standards.

\section{Conclusions}

The article presents a new, original method supporting the recycling-oriented product assessment based on the total recycling rate-CWR (Dostatni et al. 2014), implemented into an agent system. The CWR rate is a sum of three subindices. The subindices are minimants: the lower their value, the easier the recycling. It was assumed that based on the value of the total recycling rate, the classification of product elements, and knowledge gathered during previous design works, the agent system suggests design modifications to improve the recycling-oriented assessment of the designed product.

The method takes into account the cost of recycling. Two basic factors have been considered: the first is the cost of disassembly, and the other is the cost of disposal and recycling of materials used in the product. The use of the agent technology to support the design of environmentally friendly products enabled the automation of the decision-making process in design and the use of the system in design offices with distributed structure.
The agent system, together with the recycling product model implemented into a CAD 3D system, is an innovative tool for designers, facilitating comprehensive product evaluation in terms of its recyclability. It should be noted, however, that the changes proposed by the system are only hints and suggestions. The final decision must be made by the designer, who takes into account also other aspects, particularly product functionality, productibility, price and suitability for the user.

Acknowledgments This study was funded by National Science Centre Poland (Grant No. N N503 242338).

\section{Compliance with ethical standards}

Conflict of interest The author declares that there is no conflict of interests regarding the publication of this paper.

Open Access This article is distributed under the terms of the Creative Commons Attribution 4.0 International License (http://creativecomm ons.org/licenses/by/4.0/), which permits unrestricted use, distribution, and reproduction in any medium, provided you give appropriate credit to the original author(s) and the source, provide a link to the Creative Commons license, and indicate if changes were made.

\section{References}

Amruta M, Sheetal V, Mukhopadhyay D (2014) Agent based negotiation using cloud: an approach in E-Commerce. In: Satapathy SC, Avadhani PS, Udgata SK (eds) 48th annual convention of Computer Society of India (CSI), ICT and critical infrastructure: proceedings of the 48th annual convention of Computer Society of India-Vol I Book Series: Advances in intelligent systems and computing, vol 248, pp 489-496

Aziz ASA, Hanafi SE, Hassanien AE (2014a) Multi-agent artificial immune system for network intrusion detection and classification. In: DeLaPuerta JG, Ferreira IG, Bringas PG, Klett F, Abraham A, DeCarvalho ACPLF, Herrero A, Baruque B, Quintian H, Corchado E (eds) International joint conference SOCO'14-CISIS'14ICEUTE'14, Book Series: Advances in intelligent systems and computing, vol 299, pp 145-154

Aziza R, Borgi A, Zgaya H (2014b) A multi-agent simulation: the case of physical activity and childhood obesity. In: Omatu S, Bersini $\mathrm{H}$, Corchado JM (eds) 11th international symposium on distributed computing and artificial intelligence (DCAI), Book Series: Advances in intelligent systems and computing, vol 290, pp 359367

Bąbiński C (1964) Engineering in industrial design (in Polish). WNT, Warsaw

Berge C (1989) Hypergraphs. North-Holland, Amsterdam

Bigus JP, Bigus J (1998) Constructing intelligent agents with Java. A programmer's guide to smart applications. Wiley Computer Publishing, New York

Brenner W, Zarnekow R, Wittig H (1998) Intelligente Softwareagenten Grundlagen und Anwendungen. Springer, Berlin

Caglayan AK, Harrison CG (1998) Intelligente Software-Agenten. Carl Hanser Verlag, München

Costa P, Mottola L, Murphy AL, Picco GP (2006) Teenylime: transiently shared tuple space middleware for wireless sensor networks. In: MidSens '06 proceedings of the 1st international workshop on middleware for sensor networks, Melbourne, pp 43-48 
Dent V, Harris S, Hall W, Martinez K (2001) Agent technology concepts in a heterogeneous distributed searching environment. VINE J Inf Knowl Manag Syst 31(2):55-63

Directive 2002/95/EC (2003) of the European Parliament and of the Council of 27 January 2003 on the restriction of the use of certain hazardous substances in electrical and electronic equipment (RoHS)

Directive 2005/32/EC (2005) Ecodesign for energy-using products (EuP)

Dostatni E, Diakun J, Hamrol A, Mazur W (2013) Application of agent technology for recycling-oriented product assessment. Ind Manag Data Syst 113(6):817-839. doi:10.1108/IMDS-02-2013-0062

Dostatni E, Diakun J, Karwasz A, Grajewski D, Wichniarek R (2014) Ecodesign of products in CAD 3D environment with the use of agent technology (in Polish). Publishing House of Poznań University of Technology, Poznań

Ellis DO (1962) Systems philosophy. Prentice-Hall, Englewood Cliffs

Frayret JM, D'Amours S, Rousseau A, Harvey S, Gaudreault J (2007) Agent-based supply chain planning in the forest products industry. Int J Flex Manuf Syst 19(4):358-91

Freeman E, Hupfer S, Arnold K (1999) JavaSpaces: principles, patterns, and practice. Addison Wesley, Reading

Hilletofth P, Lättilä L (2012) Agent based decision support in the supply chain context. Ind Manag Data Syst 112(8):1217-1235

ISO/TR 14062 (2001) Environmental management-integrating environmental aspects into product design and development

Jennings N, Wooldridge MJ (1998) Agent technology: foundations, applications, and market. Springer, Berlin

Lu T, Yih Y (2001) An agent-based production control framework for multiple-line collaborative manufacturing. Int $\mathrm{J}$ Prod Res 39(10):2155-76

Nilsson F, Darley V (2006) On complex adaptive systems and agentbased modeling for improving decision-making in manufacturing and logistics settings. Int J Oper Prod Manag 26(12):1351-1373
Park YJ, Choi HR, Kim HS (2003) Automated negotiation for order transactions of injection mold manufacturer. In: Proceedings of ICEC2003, Pittsburgh, PA, vol 5, pp 488-497

Pessin G, Sales DO, Dias MA, Klaser RL, Wolf DF, Ueyama J, Osório FS, Vargas PA (2013) Swarm intelligence and the quest to solve a garbage and recycling collection problem. Soft Comput Methodol Appl 17(12):2311-2325

Rao AS, Georgeff MP (1991) Modeling rational agents within a BDI architecture. In: Guru R (ed) Proceedings of the international conference on principles of knowledge representation and reasoning (KR-91). Morgan Kaufmann, San Mateao, pp 473-484

Shen W, Norrie DH, Barthe JP (2000) Multi-agent systems for concurrent intelligent design and manufacturing. CRC Press, London

Van Dyke PH (1996) What can agents do in industry, and why? In: Proceedings of PAAM. No. April, London, pp 205-23

Weiss G (1999) Multi-agent systems: a modern approach to distributed artificial intelligence. MIT Press, Cambridge

Weiss Z, Dostatni E (2011) Decisions made in the product design process which involve recycling. In: Knosala $\mathrm{R}$ (ed) Conference proceedings computer integrated management (in Polish), Zakopane

Woldt WE, Dvorak BI, Dahab MF (2003) Application of fuzzy set theory to industrial pollution prevention: production system modeling and life cycle assessment. Soft Comput 7(6):419-433

Wooldridge MJ (1999) Intelligent agents. In: Weiss G (ed) Multiagent systems. MIT Press, Cambridge, pp 27-77

Yu R, Iung B, Panetto H (2003) A multi-agent-based e-maintenance system with case-based reasoning decision support. Eng Appl Artif Intell 16:321-33 